\title{
Chapter 14: Where To From Here? Principles for a New Debate
}

\section{A. J. Brown and Jennifer Bellamy}

As the chapters in this book have demonstrated, the relationship between subnational regionalism and federalism remains an enduring dilemma in Australian public policy. In response to globalisation and increasing demands for social, economic and environmental sustainability, the role of local and regional governance has re-emerged as an important practical and political issue for the restructuring of the federal system of governance. This is not as a result of some 'high theory' of regionalism as a sociological construct, nor political activism for devolutionary change based on particular constitutional ideologies. While both sociological theory and constitutional ideology form part of our history of debate about the place of local and regional governance in the federal system, the rationale for reform that emerges from this book commences with more immediate public policy considerations.

Seen from different spatial, policy and governmental perspectives - rural, urban, coastal, environmental, economic, social, state, local and national - the place of Australia's regions in the federal system raises some practical questions about the quality of governance including its impacts and outcomes. The first point of consensus between these different perspectives is that the evolution of state, regional and local institutions is a vital issue for the future of the federal system. In other words, making federalism work is not simply a matter of continual improvement in public administration, or fine-tuning intergovernmental relations between the Commonwealth and existing state governments, but a question of structural reform involving the distribution of roles, responsibilities and governance capacities throughout our system of government.

In this sense, 'reform' is not necessarily seen by all contributors to this book as something that need involve change to written constitutional arrangements in a formal sense. However, all agree that it does require new approaches to devolution, collaboration, power-sharing and institutional capacity-building which are quite fundamental in their implications. While there is a range of views as to how these new approaches are best to be supported administratively, legislatively, or by existing or new constitutional arrangements - there is agreement that reform needs to be based on a systemic 'top to bottom' view of federalism rather than simple variation on the existing federal-state compact. It emerges as axiomatic that our national understanding of our 'regions', both in socio-demographic terms and for public policy purposes, is something very different for the most part to the six States and two Territories that form 
the membership of our federation. This fundamental disjunction is not about to be willed away by those who might wish it were otherwise.

How, then, is this enlarged reform task to be approached? History demonstrates that building effective local and regional governance within the federal system, and using this focus on devolution to improve the effectiveness, legitimacy and efficiency of the entire system, are not things that can be left to chance or 'natural selection' in the process of our political evolution. These elements of the federal reform agenda need to be addressed in a conscious and concerted way, through a program of informed restructuring. This is a process that needs to engage all policy sectors and all existing levels of government. Many questions arise about the form that the reform of regional governance should take, and how it will fit in the Australian federal system of governance. But more important than a specific institutional prescription is a debate based on the common principles that the reform proposal needs to address, in order to establish a more coherent direction.

Five principles about how to progress this debate emerge from the papers in this volume, as well as the rich discussion on the floor of the Symposium. The first is that it is a debate that needs to be open and inclusive, but informed by better and more targeted research on the challenges and opportunities that face our system of governance. Recent experience shows that good research - social, economic, historical and, wherever possible, empirical - can help dramatically narrow the points of divergence and strengthen the points of consensus on what exactly needs to be reformed in the federal system, and why. The debate in the Symposium revealed that there is often divergence in the understanding of the governance 'problem'; whether one starts from an institutional/political, economic, environmental or social perspective, a common disconnect exists for many people between the understanding of the 'reality' of practical problems at the regional level, and the possible sources or causes of the problem within the system of governance - if, indeed, the problem lies with the system at all. As a consequence, the reality of the human and social impacts of our governance system is easily a source of conflict among the many people with an interest in reform. Closing these gaps and disconnects in knowledge is critically important. Many of the chapters point to specific research needs. Chapters 10-13 also underscore the importance of more precise research into the financial and economic costs and benefits of various reform scenarios, to take the debate forward. All this needs to take place within a framework in which the goals, or perceived advantages, of alternative approaches to governance are made explicit. Such a framework is set out in the Appendix to this volume, in the form of the discussion paper commissioned by one stakeholder, the NSW Farmers' Association, as background to the Symposium. 
The second principle is the need for continued recognition - and cataloguing of the extent to which the governance challenges that need to be addressed by reform exist in common across a diversity of policy contexts and sectors. It may be that the perceived dysfunctions of current systems of governance are unique, in varying degrees, to particular types of regions and policy areas. However the contributions to this book demonstrate that the drivers for reform are strikingly similar, and call for similar devolutionary solutions, even if the problems to be solved may often be different.

The clearest example of this, demonstrated in the Symposium, is the extent to which the present deficit in regional governance capacity afflicts not only rural regions, but urban ones and, indeed, regions in varying stages of transition between rural and urban. Chapters 4,5 and 6 set out problems that are locally specific, but in which an agreed framework for devolution of governance functions, autonomies and capacities to the regional level represents a common solution. Chapters 7, 8 and 9 similarly demonstrate that while there may be differences in different contexts and policy sectors in the understanding and interpretation of sustainability, the rationale for governance reforms that would help better achieve it remains comparable, if not common. This lends considerably to both the appropriateness and feasibility of generalised reform of the federal system to support strengthened regional governance, on a national basis reinforced by the evidence in chapter 3 that public opinions and preferences with regard to the federal structure seem to vary only marginally between urban and rural communities, at least in NSW. The need for stronger local and/or regional governance is not just an urban issue, nor just a rural issue, but a truly national one.

What type of reform are we talking about in practice? The remaining principles can help ensure that the investigation of options becomes more focused, but still remains productive. The third principle to emerge from the debate is the need for clarity as to when we are talking about reform of government structures, and when we are talking primarily about reform in the configuration of government functions. There is substantial consensus that, if local and regional governance could be strengthened in tangible and enduring ways, without major reform of the political structures of federalism, that would obviously be desirable. Following theories of collaboration and 'whole of government' cooperation, and by simply devolving functions and resources to local government, such strengthening should also be achievable - at least in far greater measure than currently occurs. The question 'what structural reform?' arises as a secondary consideration, when turning to a frank assessment of the institutional requirements that are needed for the desired functional reform to indeed prove tangible and enduring. Although reform often tends to work backward from institutional options ('wouldn't it be better if we did it this way ...'), the fact is that institutional restructuring in and of itself does not necessarily lead to 
enhanced governance. Particularly if one objective is more adaptive, flexible governance systems, then creating new institutions may only lead to new points of constitutional inertia, inflexibility and atrophy.

This need for clarity in the relationship between functional and structural reform is brought into sharp relief by the question of the 'fourth tier' - the development of an increasing array of regional institutions, not constitutionally recognised and with wildly varying roles and accountabilities, but whose continuing growth demonstrates that functionally, a lot more of the 'real' work of governance is now being done at regional levels. This 'fourth tier' or 'sphere' of governance is not a hypothetical entity - it is a political, functional and institutional reality within our current federal system. While many citizens might like to move towards a more two-tiered federal-regional system of government if given the choice, the simple fact is that we are increasingly operating with a four-tiered one. The evidence is that this is more good than bad, given that each new regional body or strategy clearly arises in response to a perceived need. However, there is equally clearly a larger need for real policy debate, supported by robust research, about the nature and future of these institutions, based on wider appreciation of the reasons for their growth and proper long-range planning of the functional demands likely to continue to exist at the regional level.

A fourth principle, as a corollary to this, is that we must avoid over-simplification of the idea of 'regional governance'. The complexity of regional governance is well demonstrated by the existing political and institutional landscape. The lack of uniformity on the one hand and the diversity of approaches on the other, together with the overlap and duplication of different regional policy strategies being pursued by different jurisdictions, all raise a plethora of issues for any program focussed on strengthening governance capacity at the regional level. As revealed at the Symposium, these include issues of policy coherence and alignment; clarity in roles and responsibilities; resourcing capacity (e.g. skills, financing, knowledge); communicativeness and connectedness; devolution and sharing of power; and cost of compliance and burdens of bureaucratic red tape.

Perhaps most dramatically, it is impossible to talk about strengthening regional governance without recognising the importance of existing local governments in the reform process. Local government exists. Often it provides the only tangible or enduring institutional support, 'on the ground', for the program and policies of other levels of government, including regional programs. The presence of local government as an elected, general-purpose tier of government means that, politically, the deficits in regional governance capacity cannot be addressed unless the public legitimacy of regional institutions and strategies is faced squarely in their design - including issues of fairness in participation or process, and equity in outcomes. The under-resourced state of local government means that there are short-term gains to be made in the devolution of a greater share 
of public resources to this level, irrespective of how longer term institutional reform might unfold. Given the already centralised nature of the political system, forced amalgamation of local governments is not a logical strategy for building stronger regional capacity - it runs the risk of not just 'robbing Peter to pay Paul', but killing Peter in the process. A more sophisticated approach is needed to building local and regional capacity together, reinforcing the need for this to be undertaken as a coherent national strategy, and not a piecemeal, state-based one.

Finally, there is a need for specific reform options to be more clearly articulated, in sufficient detail to enable these to be evaluated and costed. Imagining the alternatives can easily be dismissed as 'high theorising', of no practical relevance - if we assume that there are no practical prospects of change. However, as this volume demonstrates, there is already plenty of change underway and on foot in the federal system, and the demands and needs of regional governance are not hypothetical questions. In the quest for a more informed debate about an improved federal system, specific, costable scenarios for reforms that would also strengthen local and regional governance are vital, because they will yield important lessons to help shape the reality of reform, even if any single given scenario is unlikely to provide all the answers. Most importantly, the papers in this volume confirm that we should not compromise our short-term decisions by dismissing the relevance of long-term options, any more than we should ignore short-term realities when imagining what might eventually unfold. As several contributors have argued, federation itself was a case of fundamental and systemic change which did not happen overnight, but rather incrementally over time.

Federalism is a reality; and so is regionalism. They are both vital and positive forces in all elements of our system of governance. These are the immediate starting points for a new debate about how these forces are best to be reunited and reconciled in Australian constitutionalism, political practice, and public policy. 